\title{
ESTUDO DA CORRELAÇÃO ENTRE O GRAU DE CONFORMIDADE ÀS BPA E A SEGURANÇA DO LEITE ${ }^{1}$
}

\author{
Sílvia Panetta Nascimento \\ Higiene Alimentar Publicações e Serviços/ Faculdade de Tecnologia de Itapetininga, \\ e-mail: ha.spn@uol.com.br
}

Simone Moraes Raszl

SENAI/SC, e-mail: simone@sc.senai.br

\begin{abstract}
RESUMO: A segurança dos alimentos depende fundamentalmente da forma como as matérias-primas agroalimentares são obtidas. O leite constitui-se em matéria-prima para a agroindústria de produtos lácteos, de modo que sua qualidade é fator determinante para a qualidade e segurança dos produtos dele derivados. A fim de avaliar se o emprego das Boas Práticas Agropecuárias (BPA) garante a segurança do leite produzido foi desenvolvido este Estudo, procurando-se verificar o grau de correlação entre o emprego das BPA e a segurança do leite produzido na região de Itapetininga, SP. Para tanto, foi elaborado um checklist baseado na Instrução Normativa no 51 e aplicado em propriedades rurais da região de Itapetininga, SP. Na ocasião também foram coletadas amostras do leite produzido e submetidas a análises físico-químicas e determinação de Contagem Bacteriana Total (CBT), assim como Contagem de Células Somáticas. Os resultados demonstraram que, apesar do leite analisado apresentar-se dentro dos padrões vigentes, foi verificada fraca correlação entre o grau de conformidade às BPA e a CBT, concluindo-se que, embora a adoção das BPA seja válida para a melhoria da qualidade do leite, outros fatores também influenciam em sua qualidade microbiológica e deverão ser também considerados.
\end{abstract}

Palavras-chave: Qualidade. Leite. Boas Práticas Agrícolas.

1 Trabalho de Conclusão de Curso do MBA em Gestão para Segurança de Alimentos, SENAIsc. 


\section{INTRODUÇÃO}

O leite é matéria-prima destinada a diferentes indústrias visando à obtenção de produtos derivados como queijos, doces, leites fermentados, pasteurizado, UHT, entre outros. Sua qualidade é fator determinante para a qualidade e segurança desses produtos. Diversos são os fatores que interferem na qualidade do leite, como raça, genética, alimentação, manejo, etc., entretanto, é no processo de obtenção que reside hoje um dos principais entraves para se produzir leite com qualidade. Apesar de ser um tema muito debatido e existirem regulamentações para melhorar a qualidade do leite, o problema ainda persiste, principalmente porque muitas das ações propostas não atingem o pequeno produtor.

Quando o leite é recebido com baixa qualidade, as empresas processadoras de leite não conseguem melhorar esta condição porque a pasteurização elimina os micro-organismos presentes no leite, mas não inativa as enzimas produzidas por eles e que continuarão alterando os produtos derivados, degradando a proteína, o açúcar e a gordura. Cientes dessa situação algumas empresas já estão pagando de forma diferenciada pela qualidade do leite cru.

O emprego das Boas Práticas Agropecuárias (BPA) na obtenção higiênica do leite é uma ação que independe de investimentos vultosos, mas é determinante para a obtenção de leite de qualidade. A ordenha é um momento de fundamental importância para a qualidade microbiológica do leite.

\subsection{Objetivo geral}

O objetivo geral deste trabalho foi verificar o grau de correlação entre o emprego das BPA e a segurança do leite produzido na região de Itapetininga, SP.

\subsection{Objetivos específicos}

a) Verificar o grau de conformidade em relação à Instrução Normativa no 51 na obtenção do leite;

b) Relacionar o grau de conformidade em relação à Instrução Normativa no51 com a qualidade microbiológica e físico-química do leite.

\section{REFERENCIAL TEÓRICO}

A qualidade e a segurança dos alimentos, embora tragam em si conceitos diferentes, estão intrinsecamente relacionadas e constituem-se atualmente nas principais preocupações da indústria de alimentos e dos consumidores. 
Conceituar qualidade não é simples, haja vista, a evolução que o termo sofreu ao longo dos anos, sendo primeiramente associado à conformidade às especificações, evoluindo para a satisfação do cliente e atualmente corresponde à satisfação, não apenas do consumidor, mas de todos os públicos de uma empresa, atingindo a excelência da organização (GESTÃO, 2010).

Em se tratando de alimentos, a qualidade aborda aspectos nutricionais, sensoriais, tecnológicos ou sanitários, entre outros. Entretanto, a condição sanitária é aspecto indispensável para que um alimento seja considerado de qualidade, pois a presença de contaminações de qualquer natureza revelará falta de qualidade, conforme esclarece Nogueira (2004, apud ARASAKI; OLIVEIRA; RASZL, 2009).

Considerando-se a definição de segurança dos alimentos do Codex Alimentarius (2003), associada ao termo food safety, como "a garantia que o alimento não causará dano ao consumidor quando preparado e/ou consumido de acordo com o uso a que se destina", conclui-se que a segurança é um atributo indispensável para que um alimento tenha qualidade.

A qualidade e a segurança dos alimentos são consideradas, portanto, fatores de competitividade essenciais nas cadeias de produção agroalimentares, conforme apontam Toledo et al. (2004).

No setor de leite e derivados a preocupação pela qualidade e segurança dos produtos também se faz presente e, de acordo com Milinski, Guedine e Ventura (2008), para atender às atuais tendências do mercado global por alimentos de qualidade, é necessário haver uma adequação de todo o sistema produtivo do leite, com uma interrelação entre os diversos atores envolvidos na cadeia de produção, entre eles: fornecedores de insumos, equipamentos, serviços, genética, produtores de leite, indústrias de processamento, cooperativas, empresas multinacionais e empresas comerciais importadoras.

Verifica-se, em pequenas propriedades leiteiras, problemas sanitários com o rebanho, uso de técnicas de produção pouco modernas, instalações sob condições higiênicas precárias, além da conservação do produto em condições inadequadas, o que pode comprometer todo o processo industrial (MILINSKI; GUEDINE; VENTURA, 2008). Esse fator é relevante considerando-se que aproximadamente $88 \%$ das propriedades leiteiras no Brasil, produzem um volume inferior a 50 litros diários, conforme constatado por Nogueira (2003 apud TURCO, 2003). Esses dados demonstram que quase $80 \%$ do volume de leite produzido no país procede de pequenos produtores e, de acordo com Santos e Vilela (2000), “o grande número de produtores, além de dificultar a especialização e a disseminação de informações, encarece a coleta e o controle de qualidade do leite por parte da indústria e a fiscalização pelo governo."

Apesar do desenvolvimento tecnológico atingido em certos laticínios, persistem ainda em nível de produção de leite, graves problemas que depreciam a matéria-prima e resultam em produtos beneficiados de qualidade insatisfatória (Fonseca, 1998; Nader Filho et al., 1997 apud OLIVEIRA; GALLO, 2008). Conforme afirmam Santos et al. (1999 apud ASSIS; 
FARIA; RODRIGUES, 2007), os processos de beneficiamento do leite não recuperam as características intrínsecas de um leite alterado, mas é um recurso de natureza industrial para prevenir e retardar a sua deterioração. Do ponto de vista tecnológico, a qualidade da matéria-prima é um dos maiores problemas para o desenvolvimento da indústria de laticínios no Brasil (MULLER, 2002 apud PRESOTTO; BIONDO; LUBECK, 2009).

A qualidade higiênica do leite é influenciada principalmente pelo estado sanitário do rebanho, manejo dos animais e dos equipamentos durante a ordenha e a presença de micro-organismos, resíduos de drogas e odores estranhos (BRITO; BRITO, 1998 apud NASSU et al., 2007). A preocupação em relação à saúde do consumidor é uma das principais questões envolvidas na qualidade do leite. Por ser um alimento altamente perecível e susceptível a contaminações, o leite representa um potencial risco para a saúde da população consumidora, principalmente o leite cru (BANDINI et al., 1996 apud ASSIS; FARIA; RODRIGUES, 2007).

O principal parâmetro utilizado para se verificar a qualidade do leite é o seu perfil microbiológico, através da pesquisa de grupos específicos de micro-organismos como aeróbios mesófilos, coliformes e psicrotróficos (CHAMBERS; GUIMARÃES, 2002, apud NERO; VIÇOSA; PEREIRA, 2009). Apesar de existirem padrões microbiológicos regulamentados por legislação específica, o produtor no Brasil ainda trabalha em condições muito aquém dos padrões técnicos recomendados (D'ANGELIS et al., 2004 apud ASSIS; FARIA; RODRIGUES, 2007).

Os produtos lácteos tem merecido destaque como veículo de transmissão de doenças alimentares comumente relacionadas a surtos. Contaminações por Staphylococcus aureus, Salmonella $s p$ e Listeria monocytogenes entre outros, foram verificadas em leites cru e pasteurizado e em seus produtos derivados (De BUYSER et al, 2001 apud CARVALHO, 2003).

Diversos estudos tem demonstrado a contaminação do leite por micro-organismos patogênicos no Brasil (ALVES et al., 2009; CATÃO; CEBALLOS, 2001 apud CARVALHO, 2003; CITADIN et al., 2009).

Dada a importância da matéria-prima na produção de produtos lácteos, torna-se fundamental a necessidade de implantação de medidas que visem o aumento de sua qualidade e, consequentemente, do produto final e, segundo afirma Nassu et al. (2007), a aplicação das BPA, é essencial para elevar a qualidade do leite que chega à indústria resultando no aumento da qualidade de todos os derivados.

As Boas Práticas orientam a produção de leite com qualidade, através do estabelecimento de práticas corretas de ordenha e de higienização dos equipamentos, bem como de instalações adequadas e funcionários capacitados para executar esses procedimentos (BERGAMASCHI, 2010).

Ciente dos problemas inerentes à produção leiteira brasileira, foi implementada a Instrução Normativa no 51, através do Programa Nacional de Melhoria da Qualidade de 
Leite, visando o estabelecimento de critérios para a produção, identidade e qualidade do leite (MARTINS, 2004 apud CITADIN et al., 2009; BRASIL, 2002).

A referida Instrução reúne normas de produção, identidade e qualidade de leites tipos A, $B, C$, pasteurizado e cru refrigerado, além de regulamentar a coleta de leite cru refrigerado e seu transporte a granel (BRASIL, 2002). Especificamente para o Regulamento Técnico de Identidade e Qualidade de Leite Cru Refrigerado produzido nas propriedades rurais do território nacional e destinado à obtenção de Leite Pasteurizado para consumo humano direto ou para transformação em derivados lácteos, determina que a matéria-prima deva ser obtida em condições higiênico-sanitárias, seguindo os preceitos contidos na Portaria 368/ 97 que estabelece as Boas Práticas de Fabricação para Estabelecimentos Elaboradores/Industrializadores de Alimentos.

\section{PROCEDIMENTOS METODOLÓGICOS}

Foram analisadas 18 propriedades produtoras de leite na região de Itapetininga, SP. A fim de verificar a aplicação das Boas Práticas na obtenção do leite, foi elaborado um checklist baseado no Regulamento Técnico de Identidade e Qualidade do Leite Cru Refrigerado, constante da Instrução Normativa $n=51 / 2002$ (BRASIL, 2002). Este checklist foi organizado em seis itens, abordando condições das instalações e equipamentos, situação dos funcionários e da rotina de ordenha e armazenamento do leite.

A aplicação do checklist ocorreu entre setembro a novembro de 2010, em 18 propriedades leiteiras da cidade de Itapetininga, SP. As propriedades foram escolhidas em função da participação no Projeto de Fortalecimento das Pequenas Propriedades Rurais de Itapetininga - Leite, realizado em parceria com o Ministério de Minas e Energia, através do Programa Luz Para Todos, que contempla resfriadores de leite para os produtores participantes. Três dessas propriedades, porém, não fazem parte do programa, mas participaram desse estudo para haver outros dados a serem comparados, uma vez que apresentam características diversas das demais, como maior volume de produção, uso de tecnologia e maior especialização na atividade.

As quinze propriedades participantes do programa são caracterizadas por baixo volume de produção, de 30 a 100L por dia; baixa produtividade, com média entre 7 e 11L/animal/ dia; pouco uso de tecnologia, 11 da 15 propriedades adotam ordenha manual e pouca especialização, já que o leite não é a principal atividade.

No mesmo dia da aplicação do checklist, amostras de leite cru foram coletadas nas propriedades selecionadas, a fim de determinar a Contagem Bacteriana Total (CBT), Contagem de Células Somáticas (CCS), bem como propriedades físico-químicas do leite amostrado. As amostras foram transportadas sob refrigeração, imediatamente após a coleta, para os Laboratórios de Agroindústria da ETEC Prof. Edson Galvão, em Itapetininga, SP, onde foram analisadas. 
As amostras foram coletadas de acordo com as Normas de Colheita de Amostras descritas em LANARA/MA (BRASIL, 1981). Para as análises microbiológicas foram observados os procedimentos descritos na Instrução Normativa no 62/2003 do Ministério da Agricultura, Pecuária e Abastecimento, que estabelece os métodos para Análise Microbiológica para Controle de Produtos de Origem Animal e Água (BRASIL, 2003). As análises físico-químicas foram realizadas segundo os Métodos Analíticos Oficiais Físico-Químicos para Controle de Leite e Produtos Lácteos, constantes da Instrução Normativa no 68/2006 (BRASIL, 2006). Foram realizadas as seguintes análises: alizarol, acidez titulável Dornic, densidade a $15^{\circ} \mathrm{C}$, depressão do ponto de congelamento, gordura (método butirométrico), extrato seco total e desengordurado.

Com os resultados obtidos no checklist e na análise microbiológica foi realizada correlação entre o grau de conformidade à IN 51 (BRASIL, 2002) e a qualidade microbiológica do leite e, portanto, com sua segurança e qualidade. Para tanto, foi calculada a medida da correlação linear através do coeficiente de correlação de Pearson:

$$
\begin{aligned}
& r x y=\frac{\sum x y-\frac{\left(\sum \llbracket x\right)\left(\sum \llbracket y\right) \rrbracket \rrbracket}{n}}{\sqrt{\left\lfloor\sum x^{2}-\frac{\left(\sum \llbracket X\right) 2 \rrbracket}{n}\right]\left\lfloor\sum y^{2-\frac{\left(\sum \llbracket y\right)^{2}}{n}}\right]}} \text {, onde: } \\
& \mathrm{x}=\mathrm{CBT} \\
& \mathrm{y}=\text { porcentagem de conformidade à IN } 51 \\
& \mathrm{n}=\text { número de amostras } \\
& \mathrm{rxy}=\text { coeficiente de correlação de Pearson }
\end{aligned}
$$

Para o cálculo do coeficiente foi utilizado o Programa Microsoft Office Excell 2007 e interpretado o valor obtido conforme definido por Toledo e Ovalle (2008):

a) correlação linear positiva: quando valores crescentes de $x$ estiverem associados a valores crescentes de y e perfeita positiva, os pontos deverão estar perfeitamente alinhados;

b) correlação linear negativa: valores crescentes de $x$ associados a valores decrescentes de y e perfeita negativa, com pontos alinhados, mas em sentido contrário;

c) correlação nula, quando não houver relação entre as variáveis x e $y$, ou seja, quando as variações de $x$ e $y$ ocorrerem independentemente não existe correlação entre elas, neste caso $r x y=0$. 


\section{RESULTADOS E DISCUSSÃO}

Com os dados obtidos no checklist foi possível determinar o grau de conformidade de cada propriedade com os requisitos estabelecidos na Instrução Normativa no 51 (BRASIL, 2002), conforme apresentado no Gráfico 1.

As propriedades no 16, 17 e 18 tiveram 100\% de conformidade, diferentemente das demais ( $n$ - 1 a 15) que apresentaram um nível de conformidade variando de 8 a 50\%. Enquanto as propriedades de $\mathrm{n}$ - 1 a 15 trabalham com um volume diário de produção variando de 30 a 100L, as três últimas produzem de 1.500 a 2.300 L/dia. Nestas a adoção das BPA é condição indispensável inclusive para obtenção do Registro junto ao Serviço de Inspeção, o que não se verifica nas demais, muitas das quais produzem apenas para subsistência ou entregam o leite no Laticínio Municipal, onde o nível de exigências ainda é mínimo.

Gráfico1 - Grau de conformidade à IN no 51 na obtenção do leite

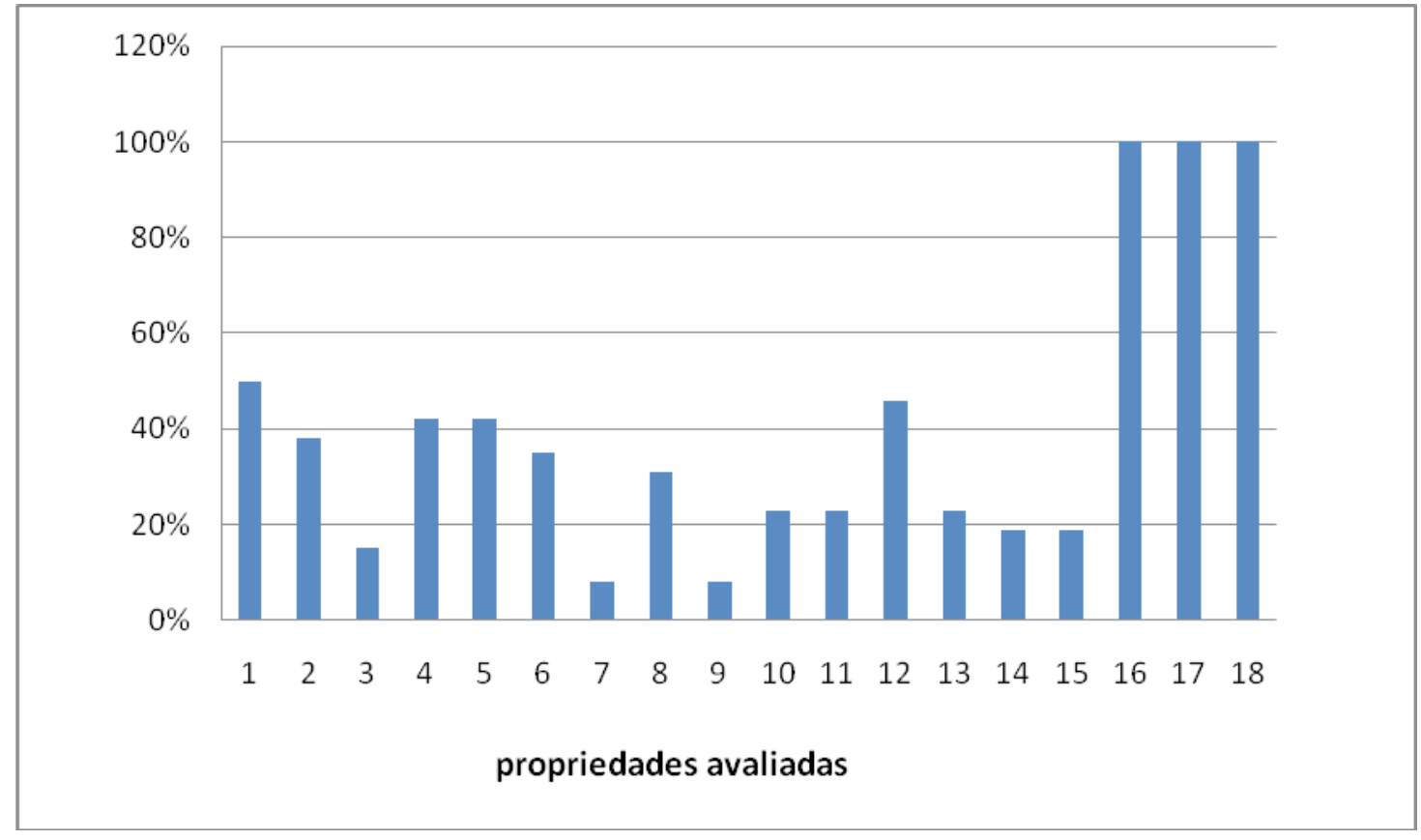

Fonte: Dados primários da pesquisa

Considerando-se a porcentagem média de cada um dos seis itens avaliados nas propriedades verifica-se no Gráfico 2, que o item 4, que avaliou as condições de higiene dos funcionários, foi o que apresentou menor grau de conformidade (20,3\%) à Normativa, a qual recomenda seguir os preceitos contidos na Portaria 368 (BRASIL, 1997), quanto aos procedimentos gerais de manipulação. Guerreiro et al. (2005 apud KRUTZMANN et al, 2008), também constataram ausência de uniformes nos responsáveis pela ordenha, entretanto, Nassu et al (2007), ressaltam que os hábitos de higiene dos ordenhadores devem ser rigorosamente observados para garantir a segurança do produto. 
Os aspectos verificados no item 5 , rotina de ordenha, também apresentaram baixo grau de conformidade $(37,7 \%)$ à IN no 51 . A lavagem dos tetos e segregação do leite alterado por mastite foram os pontos de maior conformidade, por outro lado, sistemas pré e pósdipping somente foram constatados nas três propriedades que trabalham com maiores volumes de leite. Também Nero, Viçosa e Pereira (2009), observaram maior frequência nas práticas adequadas de ordenha, em propriedades com média de produção diária superior a $100 \mathrm{~L}$.

Gráfico2 - Média do grau de conformidade de cada item avaliado nas propriedades.

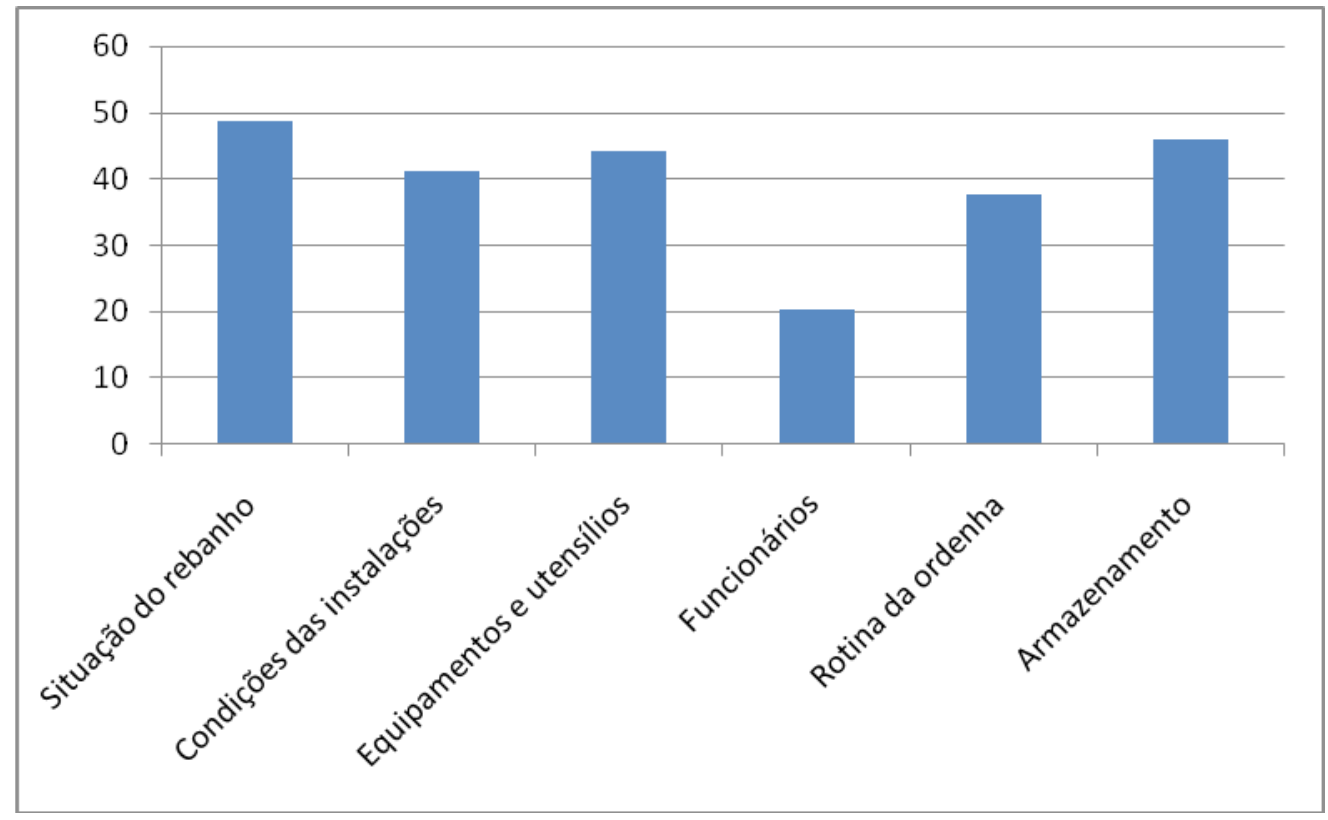

Fonte: Dados primários da pesquisa

Os demais itens tiveram uma porcentagem de adequação variando entre 41 e $48 \%$, sendo que os aspectos que tiveram maiores frequências de adequação nesses itens, e, consequentemente, contribuíram para elevar a média geral, foram: sanidade do rebanho atestada; instalações cobertas, equipamentos e utensílios adequados e filtração do leite.

Os atestados de sanidade do rebanho são um dos requisitos para participação do Projeto de Fortalecimento das Pequenas Propriedades Rurais de Itapetininga - Leite, de modo que se explica a maior frequência de conformidade observada nesse aspecto.

As instalações cobertas, apesar de presentes em 16 das 18 propriedades avaliadas, mostraram-se deficitárias nos demais aspectos considerados, como "limpeza" e "ausência de insetos e outros animais". Quanto aos resíduos orgânicos, foram observadas péssimas condições em algumas propriedades. 
Os valores obtidos nas análises físico-químicas das amostras de leite coletadas encontram-se no quadro 1, onde é possível verificar, para o Teste do Alizarol, que $72 \%$ das amostras de leite apresentaram resposta normal em relação à acidez. Duas amostras foram consideradas ácidas e três amostras apresentaram coloração normal, porém, com presença significativa de grumos. Estas, no entanto, apresentaram valores de acidez titulável dentro do intervalo estabelecido pela legislação, de 14 a 18으. D. Apenas uma amostra apresentou acidez acima do estabelecido, a qual também foi considerada ácida no teste do Alizarol.

De modo geral, pode-se afirmar que acidez elevada é indicativa de uma alta contaminação bacteriana no leite (PEIXOTO; MOURA; FARIA, 1985), o que foi constatado na amostra 8 que excedeu o valor limite para acidez titulável, assim como o estabelecido para contagem bacteriana total (Quadro 2).

\begin{tabular}{|l|l|l|l|l|l|l|l|}
\hline \multirow{2}{*}{ Amostra } & Acidez & Densidade a & Crioscopia $\mathrm{a}^{\circ} \mathrm{H}$ & Gordura \% & ST\% & ESD\% \\
\cline { 2 - 7 } 01 & Alizarol & ${ }^{\circ}$ Dornic & $15^{\circ} \mathrm{C}$ & & & & \\
02 & precipitado & 18 & 1,030 & $-0,553$ & 3,1 & 11,47 & 8,37 \\
\hline 03 & grumo & 17 & 1,032 & $-0,543$ & 3,1 & 11,98 & 8,88 \\
\hline 04 & normal & 18 & 1,033 & $-0,543$ & 3,3 & 12,48 & 9,18 \\
\hline 05 & normal & 17 & 1,033 & $-0,542$ & 4,0 & 13,31 & 9,31 \\
\hline 06 & normal & 16 & 1,031 & $-0,522$ & 4,0 & 12,81 & 8,81 \\
\hline 07 & normal & 15 & 1,029 & $-0,552$ & 3,4 & 11,58 & 8,18 \\
\hline 08 & ácido & NR & NR & NR & NR & NR & NR \\
\hline 09 & normal & 22 & 1,033 & $-0,567$ & 3,0 & 12,12 & 9,12 \\
\hline 10 & grumo & 17 & 1,028 & $-0,460$ & 2,9 & 10,73 & 7,83 \\
\hline 11 & normal & 17 & 1,031 & $-0,544$ & 3,0 & 11,61 & 8,61 \\
\hline 12 & normal & 15 & 1,031 & $-0,550$ & 3,8 & 12,57 & 8,77 \\
\hline 13 & normal & 18 & 1,031 & $-0,537$ & 2,7 & 11,26 & 8,56 \\
\hline 14 & normal & 17 & 1,032 & $-0,549$ & 3,9 & 12,70 & 8,80 \\
\hline 15 & normal & 17 & 1,033 & $-0,534$ & 3,1 & 12,24 & 9,14 \\
\hline 16 & normal & 17 & 1,031 & $-0,546$ & 3,6 & 12,33 & 8,73 \\
\hline 17 & normal & 15 & 1,032 & $-0,544$ & 4,2 & 13,15 & 8,95 \\
\hline 18 & normal & 16 & 1,032 & $-0,548$ & 4,6 & 13,74 & 9,14 \\
\hline
\end{tabular}

Quadro 1 - Resultados das análises físico-químicas de amostras de leite cru obtidas em Itapetininga, SP, set a nov/2010.

Fonte: das autoras (2010).

Para a medida de densidade relativa, todas as amostras estavam de acordo com o estabelecido na Instrução Normativa no 51 para leite cru, ou seja, valores entre 1,028 e 1,034 . 
O limite máximo estabelecido para Índice Crioscópico na IN № 51 é de $-0,530^{\circ} \mathrm{H}$, de modo que apenas uma das amostras analisadas (amostra $n$ 은) encontrava-se abaixo desse valor.

O valor mínimo para o parâmetro matéria gorda é de $3,0 \mathrm{~g} / 100 \mathrm{~g}$, verificado em $87,5 \%$ (14) das amostras analisadas. Apenas duas amostras ( $n$ ㅇ 9 e nํ 12) não atingiram o mínimo requisitado, o que pode ser consequência de diversos fatores, uma vez que a gordura é o constituinte mais variável do leite, sofrendo interferência da raça do animal, estação do ano, período de lactação, alimentação, assim como sua relativa facilidade em se separar dos demais constituintes, acumulando-se nos recipientes sem movimentação (PEIXOTO; MOURA; FARIA, 1985).

Em relação ao extrato seco desengordurado, entretanto, a amostra no 12 mostrou-se dentro do mínimo exigido na Normativa, de 8,4 g/100g, o que pode ser explicado pelo fato dessa determinação ser resultado não apenas da matéria gorda, mas também da densidade relativa, que apresentou-se maior nessa amostra. Usando-se o mesmo raciocínio verificou-se também que a amostra $n=6$, apesar de ter apresentado teor de gordura acima do mínimo estabelecido, não atingiu o valor mínimo definido para extrato seco desengordurado, com $8,18 \%$. Neste caso a densidade relativa a $15^{\circ} \mathrm{C}$ foi de 1,029 . Ainda em relação à gordura, a amostra no 18 apresentou porcentagem bem acima da média do grupo (de $3,47 \%$ ), o que pode ser explicado pelo fato de ser proveniente de vacas da raça Jersey que, naturalmente, produzem leite com maior teor de matéria gorda.

\begin{tabular}{|l|l|l|l|}
\hline AMOSTRA & CBT & CCS & $\begin{array}{l}\text { Grau de } \\
\text { conformidade (\%) }\end{array}$ \\
\hline 01 & UFC $/ \mathrm{mL}$ & CS/ $\mathrm{mL}$ & \\
02 & $2,0 \times 10^{5}$ & Até 200.000 & 50 \\
03 & $6,0 \times 10^{4}$ & Até 200.000 & 38 \\
04 & $1,2 \times 10^{5}$ & Até 200.000 & 15 \\
\hline 05 & $6,0 \times 10^{5}$ & Até 200.000 & 42 \\
06 & $1,7 \times 10^{5}$ & Até 200.000 & 42 \\
\hline 07 & $<10^{3}$ & Até 200.000 & 35 \\
08 & $1,2 \times 10^{7}$ & NR & 8 \\
\hline 09 & $1,0 \times 10^{7}$ & NR & 31 \\
\hline 10 & $8,0 \times 10^{4}$ & Até 200.000 & 8 \\
\hline 11 & $1,8 \times 10^{5}$ & Até 200.000 & 23 \\
12 & $5,5 \times 10^{4}$ & Até 200.000 & 23 \\
\hline 13 & $6,7 \times 10^{4}$ & Até 200.000 & 46 \\
\hline 14 & $2,4 \times 10^{5}$ & Até 200.000 & 23 \\
\hline 15 & $<10^{3}$ & Até 200.000 & 19 \\
\hline 16 & $6,0 \times 10^{5}$ & Até 200.000 & 19 \\
\hline
\end{tabular}




\begin{tabular}{|l|l|l|l|}
\hline 17 & $2,1 \times 10^{5}$ & Até 200.000 & 100 \\
18 & $5,8 \times 10^{5}$ & Até 200.000 & 100 \\
\hline
\end{tabular}

Quadro 2 - Resultados das análises de Contagem Bacteriana Total (CBT) e Contagem de Células Somáticas (CCS)

Fonte: das autoras (2010).

A Instrução Normativa no 51 foi implementada gradativamente respeitando-se a diversidade de situações existentes nas diversas regiões do País, de modo que na região Sudeste (onde foi desenvolvido este estudo), o limite estabelecido para bactérias aeróbias mesófilas em leite cru, a partir de 01 de julho de 2008 e vigente até 01 de julho de 2011, é de 7,5 x $10^{5} \mathrm{UFC} / \mathrm{mL}$. Desta forma, apenas duas (12,5\%) das amostras analisadas apresentaram-se em desacordo com a legislação (Brasil, 2002) no momento do estudo. Entretanto, Chambers (2002 apud NERO; VIÇOSA; PEREIRA, 2009) alerta que valores superiores a $10^{5} \mathrm{UFC} / \mathrm{mL}$ já são indicativos de sérios problemas higiênicos na obtenção, conservação e transporte do leite cru, constatação esta provavelmente responsável pela meta final de qualidade microbiológica pretendida pela Normativa, a partir de julho de 2011.

Considerando-se como parâmetro o novo valor a ser previsto para ser atingido em 2011, então, $66,7 \%$ das amostras pesquisadas neste estudo demonstram problemas higiênicos na produção do leite, situação também verificada por Nero, Viçosa e Pereira (2009), quando constataram que $60 \%$ das amostras de leite cru analisadas apresentaram valores superiores a $10^{5} \mathrm{UFC} / \mathrm{mL}$. Citadini et al. (2009), encontraram situação pior, ao pesquisarem a qualidade microbiológica do leite cru obtido em propriedades de Marechal Cândido Rondon, PR, onde 80,6\% das amostras analisadas apresentaram valor acima desse limite. Para Krutzmann et al. (2008), que avaliaram a qualidade microbiológica do leite em diferentes sistemas de ordenha, os resultados médios encontrados para Contagem Bacteriana Total em leite cru, demonstraram que a contaminação bacteriana independe do sistema de ordenha adotado, encontrando em todos os sistemas avaliados valores acima de $10^{5} \mathrm{UFC} / \mathrm{mL}$.

Em relação à contagem de células somáticas (CCS), a IN no 51 estabelece valor máximo de $7,5 \times 10^{5} \mathrm{UFC} / \mathrm{mL}$ e, a partir de 01 de julho de 2011, o valor máximo passa a ser de $4,0 \times 10^{5} \mathrm{UFC} / \mathrm{mL}$. Nas amostras em que foi realizada essa determinação, todas estavam em conformidade com a legislação vigente. Em duas amostras ( $n$ o 7 e 8) não foi possível determinar a CCS em função das amostras terem coagulado pela elevada acidez. As mesmas também apresentaram contagem bacteriana total acima do limite máximo previsto na Normativa.

O coeficiente de correlação determinado entre a contagem bacteriana total e a porcentagem de conformidade à IN no51 foi de 0,08 (8\%), conforme se observa no Gráfico 3. 
Gráfico3 - Correlação entre o grau de conformidade à IN № 51, em porcentagem, e a Contagem Bacteriana Total, em UFC/ mL.

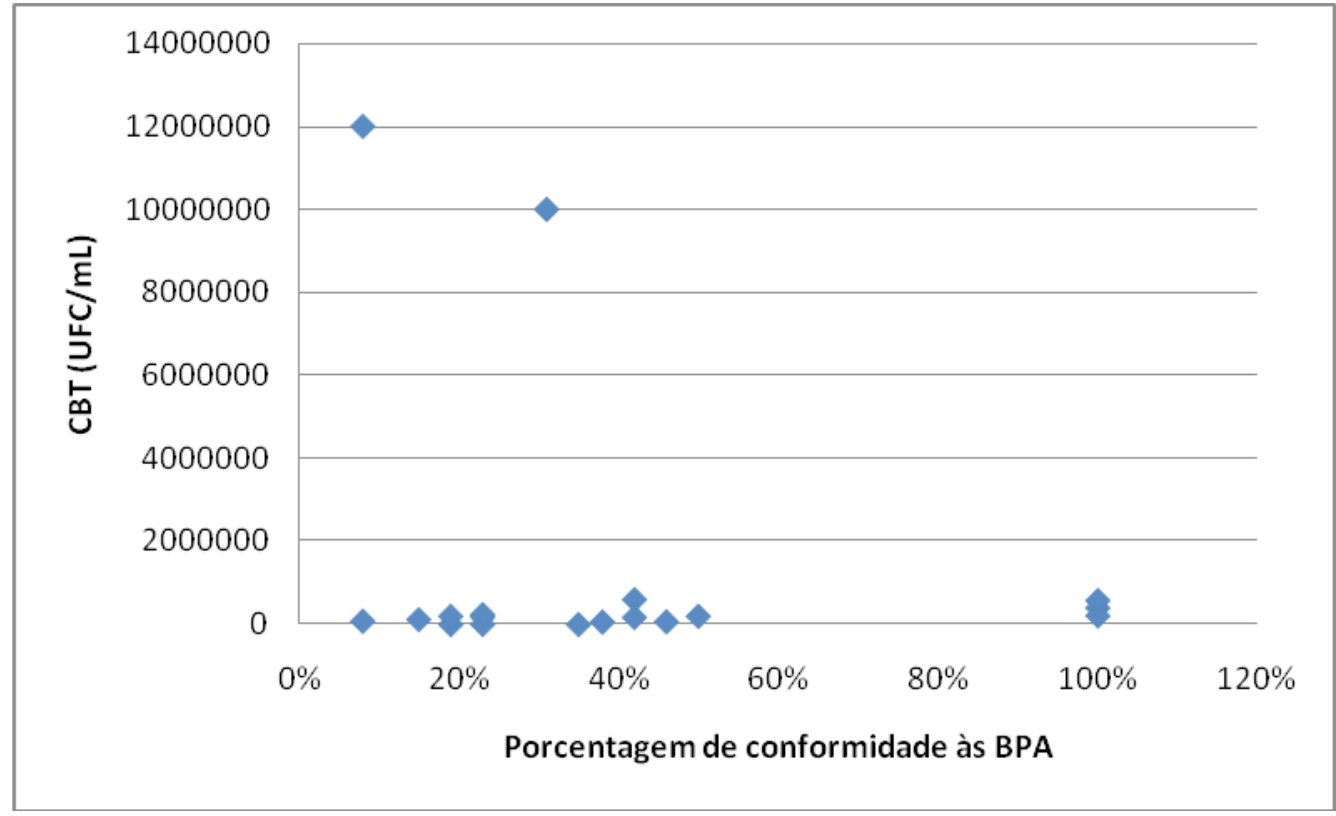

Fonte: Dados primários da pesquisa

Deste modo, o presente estudo mostrou uma fraca correlação entre a Contagem Bacteriana Total e a porcentagem de conformidade à IN no 51. É importante ressaltar, entretanto, que $87,5 \%$ dos valores de CBT encontrados estão conformes ao exigido atualmente pela IN no 51 e a média para o grau de conformidade encontrado nas propriedades amostradas, foi de $40 \%$. Esses dados revelam que, apesar de não ter sido verificada a correlação, pelo fato das contagens estarem dentro dos padrões vigentes e haver um nível médio significativo de conformidade, a adoção de boas práticas é uma ferramenta válida para a melhoria da qualidade do leite, conforme concluíram Nero, Viçosa e Pereira (2009), ao verificarem que a adoção de práticas higiênicas pelos produtores, resultou em menores contagens médias de aeróbios mesófilos. Não obstante, a adoção das boas práticas não pode ser considerada uma medida exclusiva para a obtenção de leite de qualidade já que existem outros fatores interferentes na contagem bacteriana total (CBT).

Neste estudo também não houve diferença significativa na CBT entre as propriedades com maior volume de produção (amostras № 16, com 2000 L/dia; $n$ 17, com 2.300 L/dia e $\mathrm{n}$ - 18, com $1.500 \mathrm{~L} / \mathrm{dia}$ ) e as de menor volume de produção (amostras de $\mathrm{n}-1$ a 15, com média de $60 \mathrm{~L} / \mathrm{dia}$ ), conforme pode ser verificado na Tabela 3. O grau de conformidade às BPA, entretanto, foi de $100 \%$ nessas propriedades, constatando-se que outros fatores, além da adoção das BPA interferem na CBT.

Os menores níveis de conformidade encontrados nas propriedades foram relativos às condições de higiene dos funcionários $(20,3 \%)$, os quais não adotam os procedimentos recomendados na Normativa, bem como quanto à rotina de ordenha $(37,7 \%)$, principalmente nas práticas de desinfecção dos tetos. Os demais itens avaliados mostraram uma porcentagem de adequação variando entre 41 e $48 \%$, sendo que os aspectos 
que tiveram maiores frequências de adequação nesses itens, e, consequentemente, contribuíram para elevar a média geral, foram: sanidade do rebanho atestada; instalações cobertas, equipamentos e utensílios adequados e filtração do leite.

O grau de correlação entre a CBT e a porcentagem de conformidade à IN no 51 encontrado neste estudo revelou-se fraco, com apenas 0,08 (8\%). Este fato remete para outra realidade: a de que existem outros fatores a serem considerados, para a total compreensão da relação entre as boas práticas e a qualidade do leite produzido.

\section{CONCLUSÃO}

Os resultados obtidos neste estudo demonstram que o leite obtido nas propriedades rurais avaliadas encontra-se dentro dos padrões vigentes em relação as suas características físico-químicas, com percentual de adequação acima de $89 \%$ e quanto às características microbiológicas, $87,5 \%$ dos valores de Contagem Bacteriana Total (CBT) encontrados estão conformes ao exigido atualmente pela IN 51, estando também dentro do limite aceitável para Contagem de Células Somáticas (100\%).

Embora os valores obtidos para as análises físico-químicas e microbiológicas encontraremse de acordo com os padrões vigentes, a adoção das Boas Práticas Agropecuárias nas propriedades avaliadas ainda é restrita, revelando um grau de conformidade médio de $40 \%$. Esta situação é preocupante, quando se considera o novo limite para CBT a ser adotado pela Instrução Normativa no 51, a partir de julho/2011, de 1 × $10^{5} \mathrm{UFC} / \mathrm{mL}$. Neste caso apenas 33\% das propriedades estariam em conformidade com a legislação e essa contagem indica que as propriedades apresentam problemas higiênicos na obtenção e conservação do leite cru.

No entanto, uma vez que a CBT apresentou-se dentro dos padrões vigentes e ter sido verificado um nível médio significativo de conformidade às boas práticas, pode-se considerar ser esta uma ferramenta válida para a melhoria da qualidade do leite, ainda que não deva ser considerada uma medida exclusiva para a garantia da segurança do leite, já que existem outros fatores interferentes na CBT. 


\title{
CORRELATION ANALYSIS BETWEEN THE RANGE OF CONFORMITY TO GAP AND MILK SAFETY
}

\begin{abstract}
Food safety basically depends of the manner of production of primary goods. Milk is an important primary good for dairy products and its quality is the main factor to guarantee quality and safety of milk derived products. The objective of this study was to evaluate if the adoption of the Good Agricultural Practices (GAP) could guarantee milk safety and the grade of correlation between the adoption of GAP and milk safety produced in farms from Itapetininga, SP. The evaluation of the GAP adoption used a checklist based on the Agricultural Ministry legal instruction $\mathrm{n}-51$ that was applied on those farms. At that time there were samples collected from those farms to analyze physical-chemical characteristics and Total Bacteria Count (TBC), Somatic Cell Count (SCC). Results showed that although the milk analyzed was according to legal standards, there was a weak correlation between GAP adoption and TBC. In conclusion, even thou the importance of the GPA adoption to improve mil quality, there are other factors that influence milk microbiological quality and should be considered.
\end{abstract}

Key-words: Quality. Milk. Good Agrocultural Practices.

\section{REFERÊNCIAS}

ALVES, L.M.C. et al. Qualidade microbiológica do leite cru e de queijo de coalho comercializados informalmente na cidade de São Luís - MA. Pesquisa em Foco, São Luís, v.17, n.2, p.1-13, 2009.

ARASAKI, K. M.; OLIVEIRA, K.O.; RASZL, S. M. Sistemas de Gestão da Segurança dos Alimentos. Florianópolis: SENAI, 2009.

ASSIS, E.M.; FARIA, M.G.; RODRIGUES, F.C. Qualidade do leite e efeitos de seu consumo sobre a saúde. Revista Higiene Alimentar, São Paulo, v.21, n. 156, p.47, nov./2007.

BERGAMASCHI, M. A. Atenção para boas práticas da produção de leite. 2010. Disponível em: <http://www.milkpoint.com.br/mercado/giro-lacteo/atencao-paraboas-praticas-da-producao-de-leite-67221n.aspx> Acesso em: 04 nov. 2010.

BRASIL. Ministério da Agricultura e Abastecimento. Métodos Analíticos Oficiais para Controle de Produtos de Origem Animal e seus ingredientes. I - Métodos Microbiológicos. Brasília, DF: 1981. 
Portaria no 368, de 04 de setembro de 1997 Regulamento Técnico sobre as condições Higiênico-Sanitárias e de Boas Práticas de Fabricação para Estabelecimentos elaboradores/ Industrializadores de Alimentos. Diário Oficial da União, Brasília, 08 set. 1997.

Instrução Normativa no 51. Diário Oficial da União, Brasília, 18 set. 2002.

Resolução no10 de 22/05/2003. Institui o programa genérico de Procedimentos Padrão de Higiene Operacional - PPHO, a ser utilizados nos Estabelecimentos de Leite e Derivados que funcionam sob o regime de Inspeção Federal.Brasília: MAPA, 2003.

CARVALHO, J.D.C. Avaliação da qualidade de queijos tipo minas frescal elaborados por diferente processos tecnológicos e comercializados em Campinas, SP. 2003. Dissertação (Mestrado em Tecnologia de Alimentos) - Universidade Estadual de Campinas, Campinas, 2003.

CITADIN, A. S. et al. Qualidade microbiológica de leite cru refrigerado e fatores associados. Rev. Bras. Saúde Prod. An., Salvador, v.10, n.1, p.52-59, jan/mar, 2009.

CODEX ALIMENTARIUS. General Principles of Food Hygiene. Adopted 1969. Amendment 1999. Revisions 1997 and 2003. CAC/RCP 1. 31p. Disponível em http:// www.codexalimentarius.net/download/standards/23/CXP_001e.pdf. Acesso em 13 nov 2011.

GESTÃO da qualidade. Disponível em: <http://www.triscal.com.br/portal/page/portal/ Triscal/Servi\%E7os\%20e\%20Consultoria/Consultoria\%20Estrat\%E9gica/Gest\%E3o\%20 da\%20Qualidade>. Acesso em: 13 dez. 2010.

KRUTZMANN, A. et al. Levantamento da qualidade microbiológica do leite cru em diferentes sistemas de ordenha. In: Congresso Internacional de Zootecnia, 10., 2008, João Pessoa. Anais... João Pessoa: Zootec, 2008.

MILINSKI, C.C.; GUEDINE, P.S.M; VENTURA, C.A.A. O Sistema Agroindustrial do leite no Brasil: uma análise sistêmica. In: Congresso Brasileiro de Sistemas, 4., 2008, Franca. Anais...Franca: Uni-FACEF, 2008.

NASSU, R.T et al Avaliação das boas praticas agropecuárias e qualidade do leite para processamento de queijo de coalho. Revista Higiene Alimentar, São Paulo, v. 21, n.154, p. 50 , set./2007.

NERO, L. A.; VIÇOSA, G. N.; PEREIRA, F. E. V. Qualidade microbiológica do leite determinada por características de produção. Ciência e Tecnologia de Alimentos, Campinas, v.29, n.2, p.386-390, abr./jun. 2009.

OLIVEIRA, R .P. S; GALLO, C. R. Condições microbiológicas e avaliação da pasteurização em amostras de leite comercializadas no município de Piracicaba,SP. Revista Higiene Alimentar, São Paulo, v. 22, n. 161, p. 112, maio/2008. 


\section{(}

PEIXOTO, A. M.; MOURA, J.C.; FARIA, V. P. Produção leiteira: problemas e soluções. Piracicaba: FEALQ, 1985.

PRESOTTO, R.; BIONDO, N.; LUBECK, I.S. Avaliação da qualidade microbiológica do leite armazenado em tanque de expansão e em tarro, identificação dos microrganismos isolados e determinação do perfil de sensibilidade aos agentes antimicrobianos. In: Congresso Brasileira de Medicina Veterinária, 35., 2009, Gramado. Anais... Gramado: SBMV, 2008. Disponível em: <http://www.sovergs.com.br/conbravet2008/anais/cd/ resumos/R0797-1.pdf> Acesso em: 28 abr.2009.

SANTOS, G. T.; VILELA, D. Produção leiteira - analisando o passado, entendendo o presente e planejando o futuro. In; Reunião Anual da SBZ, 37., 2000, Viçosa. Anais da XXXVII Reunião Anual da SBZ. Viçosa,MG: SBZ, 2000. p.231 - 266.

TOLEDO, G. L.; OVALLE, I. I. Estatística básica. 2 ed. São Paulo: Atlas. 2008.

TOLEDO, J. C. et al. Coordenação da qualidade em cadeias de produção: estrutura e métodos para cadeia agroalimentares. Gestão \& Produção, São Carlos, v.11, n.3, p.355372, set/dez 2004. Disponível em: <http://www.scielo.br/pdf/gp/v11n3/a09v11n3. pdf $>$. Acesso em: 23 nov. 2010.

TURCO, C. P. Análise do setor leiteiro brasileiro e da necessidade de marketing para sua consolidação. 2003. Trabalho de Iniciação Científica (Graduação em Medicina Veterinária) - Faculdade de Ciências Agrárias e Veterinárias - UNESP,Jaboticabal.

\section{SOBRE OS AUTORES}

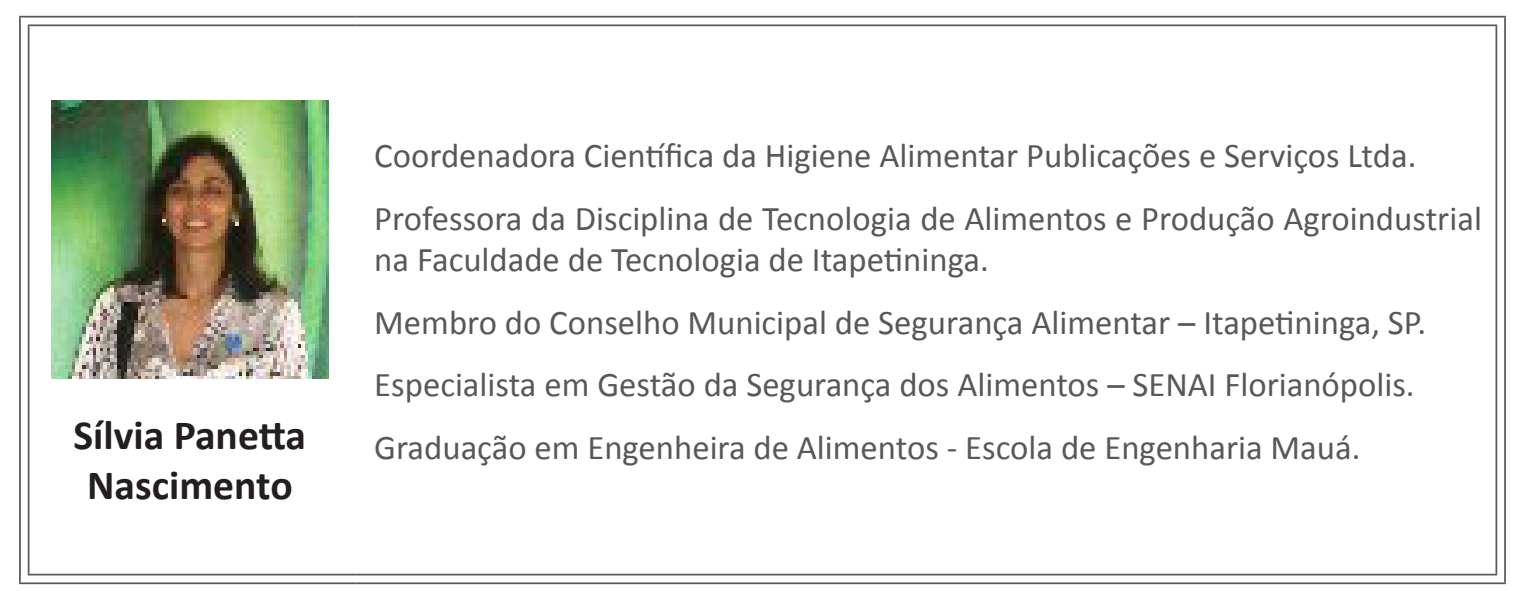




\begin{tabular}{|l} 
Médica Veterinária graduada pela Universidade Federal de Uberlândia (UFU) \\
e mestra em Ciência de Alimentos pela Universidad Autonoma de Barcelona \\
(UAB), Espanha. \\
É Lead Assessor na ISO 9001, consultora e multiplicadora do Programa Alimentos \\
Seguros (PAS) - Setor Indústria. \\
Atuou como instrutora e consultora do SENAI SC em Florianópolis para \\
implantação de Sistemas de Gestão para a Segurança de Alimentos. Foi \\
coordenadora e docente do curso de Pós-Graduação MBA em Gestão para \\
Segurança de Alimentos a distância e trabalhou na implementação e em \\
auditorias internas de Sistemas de Gestão de Qualidade e de Segurança de \\
Alimentos em diversas indústrias da área. Autora do livro Sistemas de Gestão de \\
Segurança de Alimentos, em 2008, publicado pelo SENAl e do livro Sistema de \\
Qualidade em Segurança de Alimentos: ABNT NBR ISO 22000:2006, Eurepgap \\
e BRC, publicado em 2007, pelo SENAI. Foi consultora da Organização Pan- \\
Americana da Saúde (OPAS/ OMS) em 2000-2001. \\
Atualmente é Coordenadora da Rede SENAI/SC de Educação a Distância.
\end{tabular}

